\title{
La visita de Warren Christopher
}

Hacía ya cuatro años que el país no recibía la visita de una misión diplomática estadounidense del más alto nivel como la que estuvo en suelo salvadoreño entre el 25 y 27 de febrero, encabezada por el mismo Secretario de Estado, Warren Christopher, quien se hizo acompañar, entre otras figuras de primera importancia, por el Secretario de Estado Adjunto para Asuntos Interamericanos, Alexander Watson y por la representante permanente de Estados Unidos ante la Organización de Estados Americanos, Harriet C. Babbitt. También hacía ya por lo menos ocho años, desde que en agosto de 1988 George Shultz se reuniera con los cancilleres centroamericanos en Guatemala y posteriormente recorriera las principales capitales sudamericanas (ver Proceso 347), que un Secretario de Estado no realizaba una gira por América Latina con el obvio propósito de reorientar 0 , al menos introducir ajustes relevantes, a la política exterior estadounidense para el continente.

En consecuencia, cae por su propio peso la importancia y el significado específico de la visita de Christopher a nuestro país así como el que haya sido la capital salvadoreña el lugar seleccionado para dar inicio a dicho periplo latinoamericano y, en una dimensión también regional, pero con un alcance más restringido, la sede elegida por el $\mathrm{Se}$ cretario de Estado para sostener conversaciones formales con el resto de los presidentes centroamericanos y sus representantes. Tal y como declaró en este sentido Babbitt: "el Secretario de Estado quiso comenzar su gira por el continente en El Salvador para felicitar a los salvadoreños por el progreso que han tenido. Hay mucho que hacer, pero ustedes han hecho un esfuerzo muy grande y han tenido mucho éxito. Lo que queremos hacer, como amigos de El Salvador, es seguir ayudando al proceso como podamos".

Con propósitos analíticos, entonces, podemos distinguir y delimitar claramente tres niveles en la agenda de trabajo de la misión diplomática estadounidense: el bilateral, el centroamericano y el continental.

En efecto, en el plano hemisférico, la agenda estadounidense de los últimos tiempos ha estado dominada por temas controvertidos, candentes, complejos y de muy difícil solución o erradicación como son el narcotráfico, la masiva inmigración ilegal, la extrema fragilidad de las economías de la región, la criminalidad en galopante ascenso, los recurrentes escándalos de corrupción en la esfera estatal, etc. Indicadores todos que nos recuerdan los grandes desafíos que cotidianamente mantienen en un lamentable estado de postración a nuestras naciones latinoamericanas. Quizá debido a ello, el nuevo discurso de Washington, al menos el elaborado a partir de la realización de la cumbre hemisférica de Miami, parecería reconocer que si América Latina aspira a consolidar los hasta ahora inestables y cuestionados sistemas democráticos que posee, resulta indispensable afirmar bases económicas realmente sólidas y menos inequitativas.

Sin embargo, más allá de este -a decir verdad- importante reconocimiento discursivo, en el terreno de las políticas y las medidas prácticas para responder a los susodichos desafíos, el actual gobierno estadounidense continúa empeñado en hacer énfasis en la puesta en práctica de soluciones que siguen siendo, después de todo, parciales y limitadas. Se trata, en efecto, de soluciones que 
responden más bien a la particular interpretación estadounidense de los problemas regionales así como a la defensa de sus propios intereses. De ahí que, por ejemplo, esas propuestas de solución comprendan medidas tan dispares como el establecimiento de rigurosos acuerdos de extradición, la introducción de modificaciones en las legislaciones nacionales para proteger los derechos de autor, las políticas para desalentar la inmigración ilegal, etc. Ciertamente, ninguna de estas propuestas, tal y como salta a la vista, potencia efectivamente un desarrollo económico coherente e integral tan necesario para sostener los logros conquistados en el ámbito de la democracia política, en los años ochenta, en la región.

En el plano centroamericano de la gira diplomática estadounidense, cabe señalar que los temas y problemas comunes de Estados Unidos y los países del istmo se abordaron durante una reunión de trabajo que Warren Christopher sostuvo con los presidentes de Honduras y Costa Rica, el primer ministro de Belice y los enviados personales de los presidentes de Guatemala, Nicaragua y Panamá. En realidad, buena parte de los puntos que configuran la agenda exterior estadounidense para América Latina encuentran, justamente, en los problemas que abaten a Centroamérica excelentes ejemplos de su actualidad y gravedad. Una vez más, el narcotráfico (la región es una obligada ruta de paso), el lavado de dólares, el crimen organizado, la emigración (después de México, una de las mayores de América Latina), la pobreza, la secular inestabilidad política y la severa degradación del medio ambiente constituyeron los principales tópicos de la conversación del Secretario de Estado con los mandatarios del área y sus representantes. Los resultados prácticos, empero, únicamente llegaron al terreno de las promesas de una mayor cooperación estadounidense para coadyuvar a los esfuerzos ya hechos. Igualmente, quedó también en el plano de las promesas, la primordial preocupación de los presidentes centroamericanos: un trato preferencial para sus productos de exportación en el mercado norteamericano.

Finalmente, en el ámbito bilateral, por supuesto el de mayor interés para los salvadoreños, la visita del Secretario de Estado significó un inequívoco y oportuno espaldarazo al proceso de pacificación y democratización, impulsado desde hace cuatro años a partir de la suscripción de los acuerdos de Chapultepec. No se trata, a despecho de la maliciosa y publicitada interpretación oficial, de un apoyo incondicionado y acrítico. La visita de Christopher a la asamblea legislativa y al presidente del Organo Judicial, a juzgar por el tono y el sentido de las declaraciones de los funcionarios de ambos gobiernos, constituyó un firme aunque diplomático llamado de atención al gobierno salvadoreño para concluir con el proceso de ejecución de los compromisos adquiridos sin descuidar sensibles aspectos del acuerdo de paz, pendientes de cumplimiento como la reforma política (constitucional, electoral y judicial) en curso. Por ello las palabras de Christopher ante el pleno legislativo, instando "a esta asamblea a actuar decisivamente sobre las vitales reformas constitucionales y legales que se han planteado", recibió merecidas expresiones de elogio por parte de la oposición parlamentaria. En ese mismo discurso, el Secretario de Estado también argumento que "la libertad y la paz han liberado a El Salvador para cumplir con una nueva serie de desafíos: el fortalecimiento de las instituciones judiciales, el imperio de la ley, la lucha contra el crimen y la corrupción, la protección del medio ambiente, la eliminación de la pobreza, la promoción de la integración económica $\mathrm{y}$, especialmente, el desarrollo de instituciones policiales".

En pocas ocasiones como en la presente la práctica y el discurso de un funcionario estadounidense han coincidido en el nivel real y el formal de sus objetivos. En este sentido, la presencia de Christopher en El Salvador ha significado el otorgamiento de un apoyo explícito al contenido más profundo del proceso socio-histórico salvadoreño de los últimos cuatro años: la democratización. Ciertamente, la democracia es entendida por los funcionarios estadounidenses de manera restringida. Por ella entienden la "democracia política". Por lo tanto, desde esta concepción, no se puede esperar una solución real a los males y desafíos actuales de El Salvador. No obstante, la democracia política, en sí misma, es un bien y un excelente punto de partida para buscar la solución de muchos otros problemas mayores.

De ahí que una de las principales consecuencias de la visita de Christopher haya sido colocar nuevamente en el primer plano del debate político la necesidad de apresurar todos los puntos pendientes de ejecución de los acuerdo de paz, cuya inconclusión impide cerrar completamente la fase de instauración democrática y enfrentar con mejo- 
res recursos y perspectivas los desafíos de la subsecuente etapa de consolidación. Lo anterior no debería extrañarnos, pues, precisamente nos encontramos en un período natural de evaluación global del proceso transición.

De hecho, antes de Warren Christopher nos había visitado, también en febrero, Alvaro de Soto, actual Subsecretario de Asuntos Políticos de Naciones Unidas. De esta suerte, dos figuras de gran relevancia internacional y relativamente disímiles como de Soto y Christopher han coincidido en puntos fundamentales de su evaluación sobre la marcha del proceso de pacificación y democratización. Ante todo, ambos han señalado, más allá de los avances objetivos en el terreno democrático, las debilidades e insuficiencias de nuestro proceso de cambio político. Lo anterior, obviamente, supone que la incipiente democracia no es tan sólida y profunda como argumenta el gobierno ni como lo desearían los sectores progresistas del país.

En este sentido, cabe recordar que, además del complejo problema agrario, los temas relacionados con la reforma política son los más retrasados. Se trata de poner los fundamentos estructurales de la democracia política. Por ello, tanto de Soto como Christopher han destacado, durante sus respectivas visitas, la importancia estratégica de alcanzar resultados satisfactorios en el terreno de la reforma electoral, constitucional y judicial. Estas reformas, en sí mismas, implican problemas materiales y técnicos difíciles. Pero estas dificultades se vuelven insuperables por las fuertes resistencias que encuentran en los sectores conservadores del país.

En efecto, la amplia agenda de cuestiones pendientes como la aprobación de las reformas constitucionales y electorales, la depuración del sistema judicial, la aprobación de los códigos Penal y Procesal Penal son una muestra del largo recorrido que aún tenemos por delante para construir una auténtica democracia. En realidad -y volviendo al impacto específico de la visita de Warren Christopher al país-, el tema que dominó el debate parlamentario durante la visita del Secretario de Estado estadounidense fue el de las reformas electorales pendientes.

Este paquete de reformas, negociadas y acordadas en su momento por el presidente Calderón Sol y el ex candidato a la presidencia del FMLN, Rubén Zamora, comprenden la adopción de cuatro medidas fundamentales, a saber, (a) la creación de un registro ciudadano y de un documento único de identidad; (b) la instauración del voto domiciliario; (c) la introducción de la representación proporcional en los concejos municipales; y, (d) la profesionalización del Tribunal Supremo Electoral, lo cual exige suprimir la asignación proporcional de los puestos de dirección del órgano electoral entre los principales partidos políticos del país. Hasta la fecha, ninguna de estas medidas ha sido aprobada, debido a la resistencia del gobierno.

De manera particular, el gobierno se opone decididamente a dos de esas cuatro medidas: la representación proporcional y el voto domiciliario. Para justificar su rechazo, el gobierno ha utilizado toda clase de argumentos, la mayoría de los cuales es de naturaleza retórica e inconsistente. En el fondo, el partido oficial teme que tales reformas echen a perder sus planes electorales. ARENA sabe que el sistema actual le favorece o, al menos, lo conoce suficientemente bien como para sacarle ventajas importantes. Las innovaciones propuestas

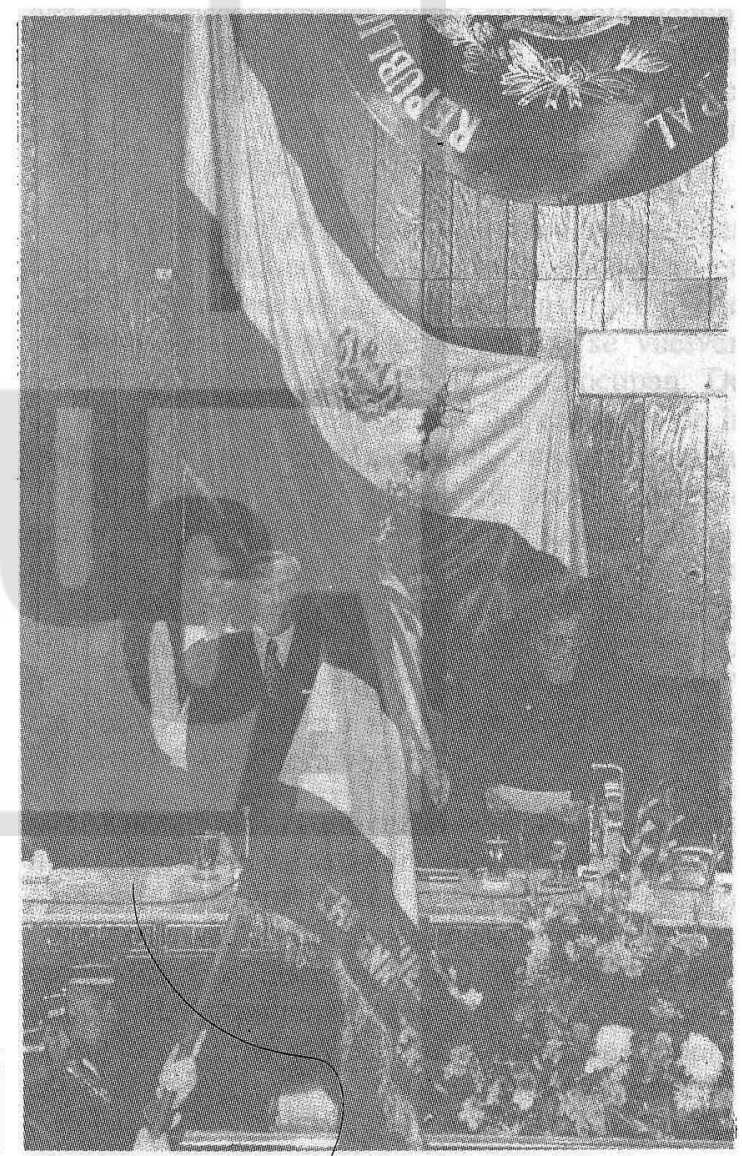


no ofrecen garantías similares. De ahí que la postergación de las reformas sea fundamental para este partido. $Y$ es que ARENA calcula que las elecciones de 1997 son cruciales para las presidenciales de 1999. Quizás para entonces haya mayor disposición para aceptar las reformas.

Al final, las reformas electorales serán aprobadas no obstante la intransigencia gubernamental, aunque es muy poco probable que puedan entrar en vigencia para las elecciones de marzo de 1997. De todas formas, es bastante obvio que hay mucho trabajo por hacer en materia electoral. La reforma electoral no es en sí misma garantía suficiente para la instauración de un orden democrático legí- timo, pero sin ella no se cumplen los requerimientos mínimos sobre los cuales se construye dicho régimen político.

Diplomática, pero firmemente, Washington ha hecho saber al gobierno de El Salvador que no está satisfecha con el estado de cumplimiento de los acuerdos de paz, puesto que aún persisten compromisos importantes retrasados o no cumplidos. Al mismo tiempo que reconoce y alaba los logros alcanzados, señala con claridad lo que aún falta frente a un gobierno que quiere dar por cerrado este capítulo de reformas y ajustes sociales y políticos.

\section{Angel Sermeño}

